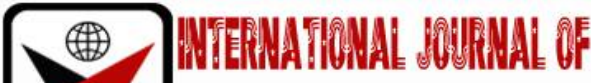

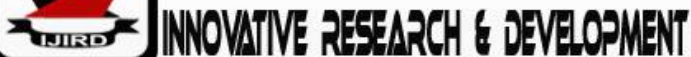

ISSN 2278 - 0211 (Online)

\section{Efficacy of Probiotic Lactobacillus Casei in Bio-control of Escherichia Coli 0157:H7 in Nono}

Ikele, M.O.
Lecturer, Department of Applied Microbiology and Brewing
Nnamdi Azikiwe University, Awka, Nigeria
Umeoduagu, N.D.
Lecturer, Department of Microbiology, Tansian University, Umunya, Nigeria
Nwakoby, N.E.
Technologist, Department of Microbiology,
Chukwuemeka Odumegwu Ojukwu University, Uli, Nigeria
Ogbukagu, C.M.
Medical Lab Scientist, Department of Medical Laboratory,
Nnamdi Azikiwe University Teaching Hospital, Nnewi, Nigeria

\section{Abstract:}

The use of chemical preservatives and non-therapeutic antibiotics for milk preservation has been an aged long practice. Although, there are specified dosages for their uses, overall fact that they are synthetic raises a need for the adoption of bio-control measures which are deemed to be natural. Lactobacillus casei is a probiotic organism indigenous to Nono. Nono is a fermented milk beverage consumed in Nigeria. This research aimed at the use of L. casei as a bio-preservative against E. coli 0157:H7 in Nono. L. casei and E. coli 0157:H7 isolates were obtained from Nono and identified with 16S rDNA sequencing. The Lactobacillus isolate was assessed for probiotic abilities. It was used in ratios of 1:1, 1:2, 1:3, 1:4, and 1:5 against E. coli in Nano preservation. The time course and pH changes were monitored over a period of 24 h. There was notable decrease in the E. coli counts within $24 \mathrm{~h}$ with 1:5 ratio of E. coli to L. casei giving the highest contaminant reduction. Likewise same 1:5 ratio gave the highest L. casei count over the 24 h monitoring. pH monitoring showed that acidity increased with increase in ratio of $L$. casei, and 1:5 ratio had the highest acidity of $4.0 \pm 0.1$. This research thus has shown that L. casei can act as a bio-control agent for the preservation of Nono from E. coli contamination. Its activity has been shown to be modulated by competitive inhibition and decrease in $\mathrm{pH}$.

Keywords: Bio-preservative, Nono, L. casei, E. coli 0157:H7

\section{Introduction}

Lactobacillus casei is a Gram positive anaerobic rod which belongs to the lactic acid bacteria (LAB) group. It is a facultative homo-fermenter found indigenous in dairy products such as Nono and cheese. Nono is a locally fermented milk beverage consumed in Nigeria. It is a functional food which contains high numbers of Lactic acid bacteria (LAB) which includes L. casei. It is usually enjoyed with a sorghum cake known as Fura and thus it is usually called Fura D’Nono. Despite its role as a functional food, unhygienic and unaseptic milking, processing, packaging and vending procedures, could render the food product susceptible to contamination with Escherichia coli and other enteric pathogens. Escherichia coli is one of the top seven pathogens of public health concern (CDC, 2014). E. coli 0157:H7 is considered an emerging disease pathogen which causes infections such as hemorrhagic gastrointestinal disease and haemolytic uremic syndrome in humans (Isibor, et al., 2013).

L. casei is well-known for its wide probiotic values such as bacteriocin production, bile tolerance, acid tolerance, ability to have a good attachment to the intestinal walls, immune modulation, cholesterol regulation, non-toxicity, antibacterial activity inter alia; and has been given Generally Recognized as Safe (GRAS) status, as there has not been any established risk to humans (Gaynor, 2012). Hence adopting it in food preservation comes with an added advantage when ingested along with the food it is meant to preserve, thus boosting the health status of the end food consumers. Biopreservation or bio-control is a measure employed as an alternative to the use of chemical preservatives and antibiotics for food preservation. Thus, this research aimed at the use of $L$. casei as a bio-control agent against E. coli proliferation in Nono. 


\section{Methods}

\subsection{Bacterial Strains, Culture Conditions and Characterization}

Lactic acid bacteria were isolated from different samples of Nono by cultivating the strains on De Mann Rogosa and Sharpe Agar (Merck) at $30^{\circ} \mathrm{C}, \mathrm{pH} 6.5$ for $24 \mathrm{~h}$ in an anaerobe jar. The strains were screened for the ability to produce antibacterial substances against $E$. coli, tolerate acidic $\mathrm{pH}$, bile and were checked for xylene adherence as described by Pringsulaka et al., (2012).

E. coli strains were isolated from same milk product by cultivation on Eosin methylene blue agar at $37^{\circ} \mathrm{C}$ for $24 \mathrm{~h}$. Isolates were screened for the ability to ferment sorbitol, and the non-sorbitol fermenting isolates were subcultured on Sorbitol McConkey agar with BCIG (Oxoid) and incubated for $24 \mathrm{~h}$ at $37^{\circ} \mathrm{C}$ as described by Isibor et al., (2013).

\subsection{Selection and confirmation of Choice Isolates}

Lactic acid bacteria with the most zone of inhibition to E. coli isolates was selected for the preservation study while the E. coli isolate was randomly selected from the Sorbitol McConkey agar plate. The isolates were confirmed using 16 s rDNA sequencing at Macrogen Laboratories South Korea.

\subsection{Standardization of Pure Cultures of Isolates}

A $0.25 \mathrm{ml}$ aliquot of pure cultures of L. casei and E. coli 0157:H7 were grown in $25 \mathrm{ml}$ MRS broth and Nutrient broth respectively and incubated in an anaerobe jar (for Lacotbacillus) and aerobically (for E. coli) without agitation at $30^{\circ} \mathrm{C}$ for $24 \mathrm{~h}$. The cultures were serially diluted using 1 in 10 -fold dilution to achieve concentrations of $10^{8} \mathrm{cfu} / \mathrm{ml}$ for $L$. casei and $10^{6} \mathrm{cfu} / \mathrm{ml}$ for E. coli according to the method described by Hartmann et al., (2011).

\subsection{Bio-preservation Tests and their Time-course Studies}

The methods of Hartmann et al., (2011) and Pringsulaka et al., (2012) were adopted to assess the efficacy of different volumes of $L$. casei in reducing viable counts of E. coli 0157:H7 in Nono. 10 ml of fresh Nono sample was dispensed into five groups of three sterile test tubes per group and pasteurized in a water bath at $60^{\circ} \mathrm{C}$ for 20 minutes. 1 $\mathrm{ml}$ of $10^{6} \mathrm{cfu} / \mathrm{ml}$ of $E$. coli was introduced into the test tubes with varied volumes of $1 \mathrm{ml}, 2 \mathrm{ml}, 3 \mathrm{ml}, 4 \mathrm{ml}$ and $5 \mathrm{ml}$ of $10^{8}$ $\mathrm{cfu} / \mathrm{ml}$ of L. casei. The set up was allowed to stand for 24 hours at room temperature and microbial counts in cfu/ml were calculated in time intervals of $4 \mathrm{~h}, 8 \mathrm{~h}, 12 \mathrm{~h}, 16 \mathrm{~h}$ and $24 \mathrm{~h}$. The $\mathrm{pH}$ of the mixtures was also noted for same time intervals.

\subsection{Statistical Analyses}

One sample T-test was used to analyze means using SPSS version 21.

\section{Results}

\subsection{Probiotic Screening of Lactobacillus Isolate}

The examined Lactobacillus isolate had good probiotic attributes which included cell free supernatant and crude bacteriocin inhibition against E. coli as shown in Table 1.

\subsection{Molecular Typing of Isolates}

The Lactobacillus and E. coli isolates were identified as Lactobacillus casei and E. coli 0157:H7 respectively with 16s rDNA sequencing.

\subsection{Bio-preservation Tests and their Time-course Studies}

There was a marked decrease in the $E$. coli count over the $24 \mathrm{~h}$ monitoring period with group E (1:5 ratio) having the least $E$. coli count as shown in figure 1. Group E also had the highest lactic acid bacteria count as shown in figure 2. Table 2 shows the $\mathrm{pH}$ variations in the set-ups and it was observed that acidity increased with increase in time and also with increase in the volume of microorganisms.

\begin{tabular}{|c|c|}
\hline Screening Parameters & Results \\
\hline Antibacterial activity against E. coli & $+(11.5 \mathrm{~mm}$ diameter zone of inhibition $)$. \\
\hline Tolerance to Acidity & + \\
\hline Tolerance to Bile & + \\
\hline Cell Hydrophobicity Test & $+(12 \mathrm{~mm}$ diameter zone of inhibition $)$. \\
\hline Crude Bacteriocin activity against E. coli & + \\
\hline Microaerophilic Growth & + \\
\hline \multicolumn{2}{|c|}{+ Table 1: Probiotic Attributes of Lactobacillus Isolate } \\
& + Positive \\
& Negative
\end{tabular}




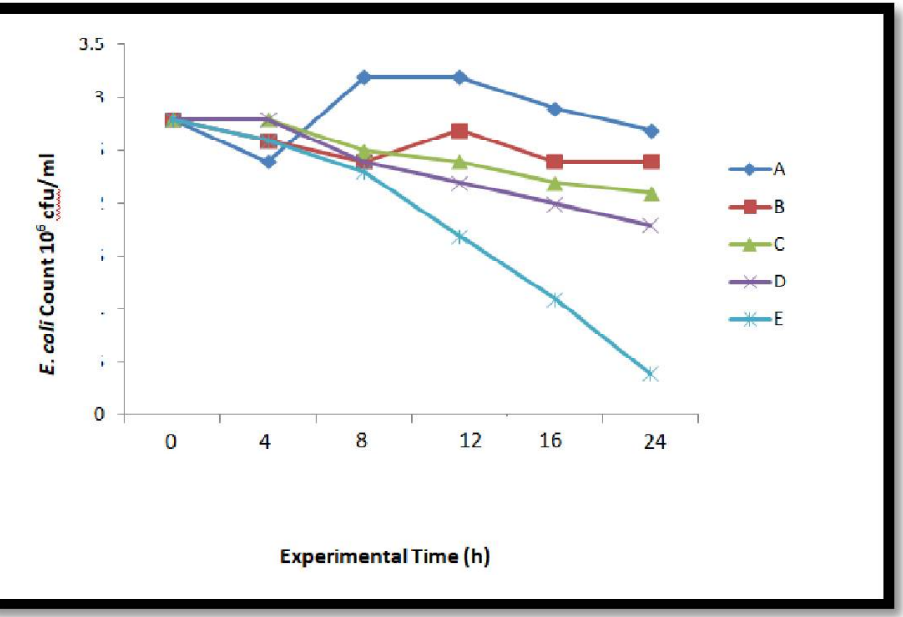

Figure 1: E. coli 0157:H7 Count in the Bio-Preservation Of Nono

$A=1: 1$ Ratio, $B=1: 2$ Ratio, $C=1: 3$ Ratio, $D=1: 4$ Ratio and $E=1: 5$ Ratio of E. Coli 0157:H7 To L. Casei.

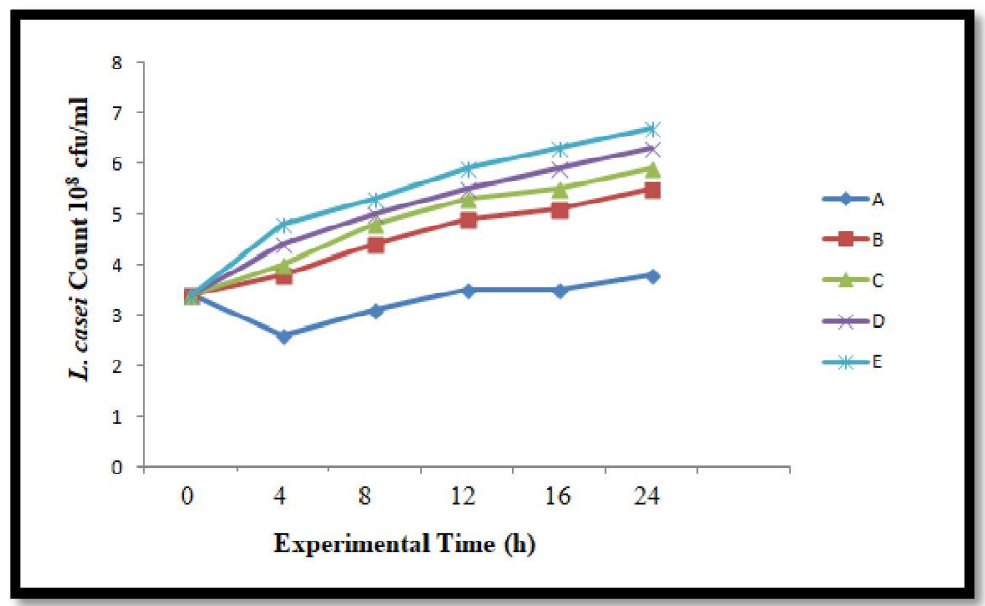

Figure 2: L. Casei Count in the Bio-Preservation of Nono

$A=1: 1$ ratio, $B=1: 2$ ratio, $C=1: 3$ ratio, $D=1: 4$ ratio and $E=1: 5$ ratio of $E$. coli $0157: H 7$ to L. casei

\begin{tabular}{|c|c|c|c|c|c|c|}
\hline Time $(\mathrm{h})$ & & & $\mathrm{pH}$ & & & \\
\hline & $\mathbf{A}$ & $\mathbf{B}$ & $\mathbf{C}$ & $\mathbf{D}$ & $\mathbf{E}$ & \\
\hline 0 & $6.1 \pm 0.1$ & $6.1 \pm 0.1$ & $6.1 \pm 0.1$ & $6.1 \pm 0.1$ & $6.1 \pm 0.1$ & \\
\hline 4 & $6.1 \pm 0.1$ & $6.1 \pm 0.1$ & $5.8 \pm 0.1$ & $5.6 \pm 0.02$ & $5.6 \pm 0.02$ & \\
\hline 8 & $5.8 \pm 0.1$ & $5.9 \pm 0.1$ & $5.5 \pm 0.01$ & $5.4 \pm 0.02$ & $5.4 \pm 0.02$ & \\
\hline 12 & $5.5 \pm 0.25$ & $5.7 \pm 0.25$ & $5.4 \pm 0.01$ & $5.1 \pm 0.01$ & $4.9 \pm 0.01$ & \\
\hline 16 & $5.3 \pm 0.1$ & $5.4 \pm 0.1$ & $5.1 \pm 0.16$ & $4.8 \pm 0.04$ & $4.4 \pm 0.05$ & \\
\hline 24 & $5.3 \pm 0.1$ & $5.1 \pm 0.1$ & $4.8 \pm 0.03$ & $4.4 \pm 0.02$ & $4.0 \pm 0.1$ & \\
\hline
\end{tabular}

Table 2: Mean $p H$ Changes in Nono during Efficacy testing of the Bio-preservative

$A=1: 1$ ratio, $B=1: 2$ ratio, $C=1: 3$ ratio, $D=1: 4$ ratio and $E=1: 5$ ratio of $E$. coli $0157: H 7$ to L. casei.

\section{Discussion}

Bio-control is a welcomed concept in food production and preservation and has been in practice for some period of time. With the world vehemently focusing on natural alternatives to the control of contaminations, infections and diseases, the use of bio-control measures is a focal method that cannot be overlooked or overemphasized. Lactobacillus species have been well researched and documented as probiotic microorganisms that also possess the ability to produce inhibitory substances commonly known as bacteriocin (Hyronimus et al., 2000). This corresponds with the probiotic attributes of L. casei as shown in table 1. Lactobacillus species are usually indigenous to dairy products especially the fermented ones. Nono is fresh milk which undergoes $24 \mathrm{~h}$ fermentation with starter culture locally called Manshanu (Makut et al., 2014). This starter culture is primarily the pre-ferment from the last fermentation batch that is stored and re-used to catalyze fermentation of new culture batches. A notable hazard threatening the safety of this product is the presence of enteric microorganisms (Abdulkadir and Mugadi, 2012). They contaminate the food, tamper with its wholesomeness and also constitute risks to the consumers. Different approaches boiling and pasteurization have been employed to tackle contamination issues associated with milk. However, heat treatment after fermentation of Nono will only result in the loss of beneficial microorganisms, especially the probiotics which would have been ingested. Therefore, 
one may resort to the use of chemical preservatives or even antibiotics, but it is still noted that these preservatives are artificial and not so advised to be used irrespective of the fact that they are applied in controlled doses. Cases of antibiotic resistant microorganisms are on the increase and thus, antibiotic use is not a comfortable preservation method to be adopted. Bio-control using probiotic microorganisms indigenous to the product appears to be a potent control measure. This is because the technique behind its application is based on increasing the numbers of the probiotics against the contaminants in the product. This initiates quorum sensing amongst the probiotic organisms and aid in their competitive inhibition against the contaminants (Holzapfel et al., 2001).

E. coli 0157:H7 is a contaminant isolated from Nono and it was also used in the establishment of bio-control efficacy of Lactobacillus casei. Both the bio-control agent and the contaminant co-habit in Nono and this basically is because they are both lactose fermenters. This observation raises a pertinent question as to why L. casei presence in Nono did not automatically inhibit the growth of E.coli in their natural habitat. A likely response to such situation is that in their natural habitat, they both make use of lactose and other nutrients in the milk to grow their cell numbers and competitive inhibition may not set in until there is nutrient depletion. Nutrient depletion could perhaps induce the Lactobacillus species to enter their stationary phase where bacteriocins and similar inhibitory substances are the produced (Joshi et al., 2006) and begin to inhibit the survival of $E$. coli in their natural habitat. This research however, provided a controlled environment for the growth of both organisms, while constantly increasing the ratio of the probiotic against the contaminant over a $24 \mathrm{~h}$ period at room temperature. Figure 1 showed that there was marked decrease in the E. coli count for all groups with group E showing the least count as time increased. Figure 2 also showed a marked increase in the $L$. casei count for all groups with group E showing the highest count as the hours of monitoring increased. Table 2 showed a decreasing $\mathrm{pH}$ value to acidic range in all the groups, reflecting the metabolism of the sugars in Nono (mainly lactose) and subsequent production of lactic acid from both microorganisms. However, Group E showed the highest acidity value of 4.0 at $24 \mathrm{~h}$, which is not a very suitable pH of growth for the pathogen E. coli 0157:H7. E. coli 0157:H7 presence in Nono as reported in this research corresponds with the report of Abdulkadir and Mugadi (2012). It could be thus interpreted that the control of E. coli 0157:H7 by L. casei was modulated by competitive inhibition based on increased cell numbers as well as by the influence of $\mathrm{pH}$.

\section{Conclusion}

This study reveals that the incorporation of increased volumes of $L$. casei to Nono will aid in bio-preservation against $E$. coli and possibly, other enteric contaminants.

\section{References}

i. Abdulkadir. M., and Mugadi, A. G. (2012). Bacteriological Examination of Fura Da Nono Sold in some Selected Areas of Birnin-Kebbi Metropolis. Asian Research Publishing Network Journal of Science and Technology 2: 333340.

ii. $\quad$ CDC (2014). General Information on Escherichia coli. www.cdc.gov, accessed on March 23, 2015.

iii. Gaynor, P. (2012). Generally Recognized as Safe (GRAS) Determination for the Use of L. casei Strain Shirota as a Food Ingredient. Center for Food Safety and Applied Nutrition. www.yakult.co.jp, accessed on February 05, 2016.

iv. Hartmann, H.A., Wilke, T. and Erdmann, R. (2011). Efficacy of bacteriocin-containing cell-free culture supernatants from lactic acid bacteria to control Listeria monocytogenes in food. International Journal of Food Microbiology 146: 142-199.

v. Holzapfel, W.H., Haberer, P., Geisen, R., Bjorkr, R. and Schillinger, U. (2001). Taxonomy and Important Features of Probiotic Microorganisms in Food and Nutrition. American journal of Clinical Nutrition 73: 365S-373S.

vi. Hyronimus, B., Le Marrec, A., Hadj, S.A. and Deschamps, A. (2000). Acid and bile tolerance of spore-forming lactic acid bacteria. International Journal of Food Microbiology 61:193-197.

vii. Isibor, J.O., Ekundayo, A.O., Ohenhen, R.E. and Orhue, P.O. (2013). E. coli 0157:H7- Prevalence and Risk Factors of Infection in Edo State, Nigeria. American Journal of Research Communication 1(3): 35-50.

viii. Joshi, V.K., Sharma, S. and Rana, N.S. (2006). Bacteriocin from Lactic Acid Bacteria. Journal of Food Technology and Biotechnology 44 (3): 435-439.

ix. Makut, M.D., Nyam, M.A., Amapu, T.Y. and Ahmed, A. (2014). Antibiogram of Bacteria

X. Isolated from Locally Processed Cow Milk Products Sold in Keffi Metropolis, Nassarawa

xi. State, Nigeria. Journal of Biology, Agriculture and Healthcare 4(4): 19-25.

xii. Pringsulaka, O., Thongngam, N., Suwannasai, N., Atthakor, W., Pothivejkul, K., and Rangsiruji,

xiii. (2012). Partial characterization of bacteriocins produced by lactic acid bacteria isolated from Thai fermented meat and fish products. Food Control 23: 547-551. 